\title{
Risk of Handling Paper Currency in Circulation Chances of Potential Bacterial Transmittance
}

\author{
Janardan Lamichhane, Satish Adhikary, Prson Gautam, Rajani Maharjan and Bishal Dhakal \\ Department of Biotechnology, Kathmandu University, Dhulikhel, Kavre, Nepal \\ e-mail : ljanandan@yahoo.com
}

\begin{abstract}
All sets of paper currency produced by the government of Nepal were collected from four major sources (transporters, butchers, food sellers, and banks) where paper currency is widely used. The currencies used by public transport in Nepal (micro-buses) were found to be extremely contaminated with various pathogenic bacteria followed by the currency used by butchers and food sellers. These microorganisms could be one of the major causes of widely transmitting diseases in Nepal. Eight different pathogenic bacteria were isolated that are the known to be involved in transmitting various diseases in Nepal. A lot of people loss their life every year in Nepal due to the transmittance of diseases by these kind of bacteria. Use of paper money could be one of the major sources of transmittance of such diseases in Nepal that provides platform for the growth of such bacteria. Public awareness of using paper currency in circulation became essential for the safety in human health.
\end{abstract}

Key words: Escherichia coli, infections, pathogens, Staphylococcus aureus, Salmonella choleraesius

\section{Introduction}

Entering the antibiotic era, it was anticipated that morbidity and mortality from infectious diseases would continue to decrease over time. However, the death rate from infectious diseases increased by $58 \%$ from 1980 to 1992, making it the third leading cause of death in the world by 1992 (Pinner et al. 1996). Furthermore, with the emergence of drug-resistant pathogens, many infections have become more difficult to treat.

A classic characteristic of human parasitic and bacterial agents is the evolution of routes for transmission to susceptible hosts. The environment plays a critical role in transmission to humans, with many environmental materials serving as vehicles (Anderson \& May 1991, Struthers \& Westran 2003). Microbial contaminants may be transmitted, either directly, through hand-to-hand contact, or indirectly via food or other inanimate objects. These routes of transmission are of great importance in the health of many populations in developing countries, where the frequency of infection is a general indication of local hygiene and environmental sanitation levels (Cooper 1991).
The possibility that currency notes might act as environmental vehicles for the transmission of potential pathogenic microorganisms was suggested in 1970s (Abrams \& Waterman 1972). Paper currency is widely exchanged for goods and services in countries worldwide. It is used for every type of commerce, from buying milk at a local store to trafficking in sex and drugs. All this trade is in hard currency, with lower-denomination notes receiving the most handling because they are exchanged many times (Gadsby 1998). Paper currency provides a large surface area as a breeding ground for pathogens (Podhajny 2004).

Money on which pathogenic microorganisms might survive represents an often overlooked reservoir for enteric disease (Michaels 2002). In most parts of the developed world, there is a popular belief that the simultaneous handling of food and money contributes to the incidence of food-related public health incidents (FSA 2000). Over the last two decades, the observed data indicated that simultaneous handling indeed was a cause of sporadic food borne-illness and survival of pathogens 
on currency notes in Turkey (Goktas \& Oktay 1992), United States (News 1998, Jiang \& Doyle 1999, Pope et al. 2002), Australia (FSA 2000), India (Singh et al. 2002), Egypt (El-Dars \& Hassan 2005), China (Xu et al. 2005), and Myanmar (Khin Nwe et al. 1989).

An investigation carried out in 1997 that involved swabbing and culturing from various coins and paper money randomly collected from doctors, laboratory staff, and other employees at a New York hospital resulted the recovery of many pathogenic microorganisms (News 1998, FSA 2000). The possibility of currency contamination with microorganisms has also been observed among food handlers. An assessment of the public health risk associated with the simultaneous handling of food and money in the food industry in Australia (Brady 2000) showed the presence of Staphylococci on the money surface. This suggested that without hygienic intervention, human occupational activities, especially those involving simultaneous money handling, could introduce the risk of crosscontamination to foods (FSA 2000). With a number of infectious intestinal diseases, a low dose of the infectious agent is capable of causing illness. Failure of food service workers to adequately sanitize hands or use food-handling tools (tongs, spoons, utensils or bakery/serving papers) between the handling of money and the serving of food could put food service patrons at risk (Michaels 2002).

Publications regarding the degree to which paper money is contaminated with bacteria are few (Abrams 1972, Khin Nwe et al. 1989, Goktas \& Oktay 1992, Jiang \& Doyle 1999, Michaels 2002, Pope 2002, Singh et al. 2002, El-Dars \& Hassan 2005, Xu et al. 2005). Scientific information on the contamination of money by microbial agents is lacking in most developing countries. This dearth of information may have contributed to the absence of public health policies or legislation on currency usage, handling, and circulation in the countries like Nepal. United States and Australia have fostered a higher level of public awareness about the potential for currency contamination by microorganisms (News 1998, Jiang \& Doyle 1999, FSA 2000, Michaels 2002, Pope et al. 2002). In the United States, a whole division of the Department of Treasury deals with what is termed "mutilated currency," and the department Web site boasts many examples of beleaguered, burned, buried, water-damaged money (Siddique 2003).
An aspect of food service that frequently causes comment, is the way a food handler prepares the food, takes money for the purchase, returns change to the customer, and then prepares food for the next customer. Anything that gets on hands can get on money. To date no outbreak of foodborne and other illness have been associated with infection from money. However evidences for the presence of pathogenic bacteria on currency frinforces the need for strict adherence to hygienic practices among money handlers who also handle food and water (Prasai et al. 2008)

The study reported here, therefore, was designed to add to the limited body of literature on microbial contamination of currency notes and to address growing community concerns about the risks associated with microbial contamination and handling of money worldwide.

\section{Materials and Methods Sampling Technique}

A total of 28 samples of Nepalese currency (the Rupees), comprising notes in all seven denominations (Rupees $5,0,20,50,100,500$ and 1000) were investigated. Coins were not sampled because their circulation rate is too low due to the depletion of currency value in Nepal. The investigation was conducted from June to August 2008 in Kathmandu the capital city of Nepal. The notes came from four different sources, butchers, food sellers, transporters and bankers. Samples were randomly obtained by using large-denomination notes to smaller denominations by respective group. The notes were then placed in a sterile polyethylene bags, sealed, and taken to the research laboratory of the Department of Biotechnology, Kathmandu University, Dhulikhel for analysis.

\section{Physical Condition of the Currency}

The currency notes were in various physical conditions and were categorized as mint, clean, or dirty/mutilated. The term mint describes currency notes that had been newly or recently produced and obtained from the banks. These notes were included in the investigation as controls. The term clean describes notes that had a clean appearance without any obvious damage. The term dirty/ mutilated describes notes that either were not clearly more than one-half of the original notes or were in such condition that the value was questionable, or were damaged, soiled, or held together with bits of sticky tape. 
Janardan Lamichhane et al./Risk of Handling Paper.

\section{Bacteriological Analysis}

Isolation of various bacterial contaminants from the currency notes was performed via standard techniques described previously (Gilchrist 1993, Singh et al. 2002). Briefly, a sterile, cotton-tipped swab moistened with sterile physiological saline was used to swab both sides of the currency notes. The swabs were directly inoculated on MacConkey agar, Nutrient agar, Brain Heart Infusion broth and Mannitol salt agar all purchased from HiMedia Laboratories, India. The pairs of inoculated media were incubated aerobically at 35$37^{\circ} \mathrm{C}$ for $24 \mathrm{~h}$ and then examined for bacterial growth according to standard protocol described by Cheesbrough (2000). The bacteria were isolated by assessing colony characteristics and Gram reaction, and by conducting various biochemical tests, including tests for indole production, citrate utilization, and urase activity; triple sugar iron (TSI) agar tests (for glucose, sucrose, and lactose fermentation); gas and hydrogen sulfide production tests; and oxidase tests, according to protocols described previously (Cheesbrough 2000). Final characterization of the bacteria was done using various bacteria identification kits such as $\mathrm{KB} 002 \mathrm{Hi}$ Assorted biochemical test kit, KB003 Hi25 ${ }^{\mathrm{TM}}$ Enterobacteriaceae Identification Kit, KB004 HiStaph $^{\mathrm{TM}}$ Identification Kit, KB005 HiStrep $^{\mathrm{TM}}$ Biochemical test Kit, KB007 HiVibrio ${ }^{\mathrm{TM}}$ Identification Kit, KB010 HiE.coli ${ }^{\mathrm{TM}}$ Identification Kit, and KB011 HiSalmonella ${ }^{\mathrm{TM}}$ Identification Kit supplied by Hi-Media laboratories (India).

\section{Results}

Out of the 24 currency notes on which bacteriological analysis was conducted, $18(75 \%)$ were found contaminated with various kinds of pathogenic bacteria. Out of these 18 notes, bacterial concentration was found high on 8 notes $(44.5 \%)$ which were dirty /mutilated compared to 10 other notes $(55.5 \%)$ that were categorized as clean. No bacteria were found on the 6 notes considered as mint. Bacteria isolated from all those notes were more than 18 different types based on their colony morphology and other structural differentiations, but only 8 of the 18 were finally characterized using the bacterial identification kit; Staphylococcus aureus (NuId3), S. epidermidis (NuIh3), Streptococcus pyogenes (NuIa1), Klebsiella pneumoniae (MAIi3), Salmonella choleraesius (MAIh1), Escherichia coli (MAIc1), Enterobacter aerogenes (MAIa2) and Enterobacter cloaceae (MAIIa2).
Contamination frequency was found related to the denomination of currency. Most prevalent contamination was found among the Rupees 10 and 5 notes $(75.2 \%)$ and least prevalent among the Rupees 500 and 1000 notes $(20.0 \%)$. Contamination was also related to the physical condition of the currency; the dirty/mutilated notes had the highest prevalence of bacterial contamination $(73.8 \%)$ and clean notes had lesser prevalence of contamination (42.9\%) with bacteria.

Bacteriological analysis found a high prevalence of contamination, with the highest prevalence observed among currency notes obtained from conductors (person that takes fare from passengers) of local microbuses $(84.8 \%)$ that run in metropolitan city, followed by butchers $(78.0 \%)$ and food sellers $(62.1 \%)$. No bacterial contamination was observed on notes sampled from the banks.

\section{Discussion}

The isolation of bacterial agents from currency notes in the study reported here confirmed that currency might be a vector playing an important role in the transmission of pathogenic microorganisms in the community. Bacterial agents that can contaminate currency notes, for example, some strains of Streptococcus and Staphylococcus, are known to have developed resistance to conventional antibiotics (WHO 2000). Escherichia coli, Enterobacter cloacae and Staphylococcus epidermidis are usually nonpathogenic but some strains can cause serious food poisoning in humans and urinary tract infections. Similarly, E. cloacae is associated with urinary tract and respiratory tract diseases. S. epidermidis is usually non-pathogenic but it is an important cause of infection in patients whose immune system is compromised. Other bacteria are pathogenic that can cause various diseases ranging from opportunistic infections in skin and other tissues to pneumonia and Toxic Shock Syndrome (TSS). Among the pathogenic bacteria isolated, Klebsiella pneumoniae is a virulent organism that can cause pneumonia typically along with urinary tract and wound infections, particularly in immuno-compromised individuals. Similarly, E. aerogenes is a nosocomial and pathogenic bacterium that causes opportunistic infections in skin and other tissues.

S. choleraesius can cause salmonellosis, an acute gastroenteritis with sudden onset of headache, 
abdominal pain, diarrhoea, nausea and sometimes vomiting. S. aureus can cause a range of illnesses from minor skin infections, such as pimples, impetigo boils, and abscesses, to life-threatening diseases, such as pneumonia, meningitis, osteomyelitis endocarditic, TSS and septicemia.

The study revealed prevalence of bacteria in paper notes which was not unexpected. Pope and co-worker (2002) demonstrated in their study in western Ohio that bacteria were capable of growing on currency notes. In addition, the relative abundance of the resident or normal skin flora, as well as transient bacteria that may be found on the skin could enhance an easy transfer to inanimate objects like currency notes (Goktas \& Oktay 1992).

This study revealed a significant association between bacteria contamination and the condition of the currency, with higher rates of bacteria contamination on the dirty/mutilated notes. This finding has very important health and economic implications, especially in underdeveloped and developing tropical nations of the world and particularly in Asia and Africa (Siddique 2003). The climatic and environmental conditions of the tropics favor the thriving of many pathogenic microorganisms, and in the face of underdevelopment, inadequate water and sanitation, crowded living conditions, lack of access to health care, and low levels of education, a greater proportion of the populace, particularly the poor, become highly susceptible to infection and disease (Anderson 1991, Gwatkin 2000). Risk of infection is increased several fold when objects that change hands at a high frequency, such as currency notes, are contaminated with microbes. The risk is by no means restricted to residents of the country in question; it might even be greater for expatriates, tourists, and visitors from other countries, who may not be immune to the pathogens.

In Nepal, poor-currency-handling culture is widespread, and there is indiscriminate abuse of currency notes. A great majority of the populace does not carry money in wallets, and squeezing of currency notes is a common occurrence. Women, especially among the unenlightened, often place money underneath their brassieres, while men place theirs in their socks. These activities not only enhance currency contamination but may also increase the risk of infection from contaminated notes. The situation is further compounded by the inability of the Nepal government to consistently withdraw old, worn-out, and mutilated notes from circulation. The presence of damaged currency notes and the failure to consistently withdraw them from circulation are common phenomena in many parts of Africa and Asia (Gadsby 1998, Podhajny 2004). The persistence of damaged or terribly mutilated notes in active circulation could elevate their contributory role in transmission of some pathogens, thereby constituting potential public health hazard. Different species of bacteria isolated on this study are similar to those studied by Khin Nwe and co-workers (1989) in Rangoon, Myanmar; Goktas and Oktay (1992) in Turkey; and Pope and co-workers (2002) in Ohio. All of these researchers strongly suggested that money plays a role in the transmission of antibiotic-resistant and potentially harmful bacterial agents. Bacteria isolated in those studies, such as coagulase-negative Staphylococcus, alpha-hemolytic Streptococcus, Enterobacter species, Acinetobacter species, non-aeruginosa species of Pseudomonas, Bacillus species, Alcaligenes species, diphtheroids, and Escherichia vulneris, do not typically cause infections in healthy people rather they have been known to cause significant infections in those with depressed immune systems, including those infected with HIV, undergoing cancer chemotherapy, or taking other medications that depress the immune system. Those bacteria may also cause infection in hospitalized patients (Emori \& Gaynes 1993).

The study reported here found relatively more prevalence of bacteria among lower-denomination notes, presumably as a result of a higher rate of handling and hand-to-hand exchange (Gadsby 1998). The results did not suggest that any one denomination was particularly susceptible to or protected against contamination, since pathogens were found on all denominations of the currency notes and were absent only on the mint notes from banks. Siddique (2003) reported that a foreign bank wins business by guaranteeing its customers with a steady supply of fresh, new currency notes in Bangladesh. This practice may not guarantee the absence of microbial contamination, but it could minimize the risk of currency-associated infection.

A significant association was established between contamination and sources of currency (Conductors, Butchers, food sellers and banks in this study), with the highest levels of contamination found among currency notes from conductors of minibuses, followed by butchers to food sellers. Khin and co-authors (1989) isolated high levels of enteric pathogens from paper- 
money samples obtained from butchers and fish mongers in a local market in Rangoon, Myanmar. In most developing countries, including Nepal, sanitation facilities at slaughterhouses and meat markets are grossly inadequate, resulting in very poor environmental sanitation, thus enhancing crosscontamination from simultaneous handling of money and animal products. Major cities in Nepal, as in other developing countries, are witnessing an influx of child labors. Most of these individuals searching for the unskilled job especially hanging on the doors of the three wheelers or microbuses and buses and live under severely unhygienic conditions, appear sick, and sometimes have putrefying sores on their bodies. It was not surprising that currency notes obtained from them were highly contaminated.

Inability to quantify the cell numbers of the bacterial agents and failure to take into account the possible presence of other categories of potential pathogens, such as viruses and fungi that might contaminate currency notes are some of the limitations observed in this study, which may be the work for future research. Furthermore, we could not confirm that the identified pathogens could be transmitted from person to person because of the exchange of paper currency. We could only recommend that the paper notes used in this country are more vulnerable for the transmission of bacterial diseases and more complex study be undertaken, using molecularbiology tools, to achieve and confirm their level of vulnerability.

The results of the study reported here suggest that paper currency might be contaminated with bacteria especially in the tropics. Therefore handling of paper currency deserves special attention. The practice of licking or applying saliva to the fingers while counting paper money is worth mentioning as an important potential route of exposure to bacteria and enteric pathogenes. Strategies to reduce the contamination of currency, especially where environmental conditions favor the abundance of many pathogens, are recommended. Such strategies could include the introduction of plastic currency, which can be washed easily, as was done in Australia (the first country to do so) in 1988 (Brady 2000). Other recommendations are the washing hands thoroughly by food handlers, whether at a restaurant or at home; after handling currency and before handling food, regular disinfection of currency deposited in banks and post offices by ultraviolet light or formalin vapors (Singh et al. 2002), regular withdrawal of damaged notes by federal authorities, and, most important, the improvement of personal hygiene. Spivack (2005) has noted the possibility of terrorists contaminating banknotes with pathogens and then putting those notes back into circulation. Regular microbial testing of currency notes and establishment of a method for large-scale replacement of contaminated notes are recommended by Spivack along with other public health measures. Finally, we recommend that similar studies on the microbial contamination of currency be undertaken in other countries to enrich the global information bank on the subject; the issue is becoming a major public health concern worldwide.

\section{Reference}

Abrams, B.L. and N.G. Waterman. 1972. Dirty money. Journal of American Medical Association 219: 1202-1203.

Anderson, R.M. and R.M. May. 1991. Infectious diseases of humans, dynamics and control. Oxford University Press, New York.

Brady, G., and J. Kelly. 2000. The assessment of the public health risk associated with the simultaneous handling of food and money in the food industry. Central Goldfields Shire Council, Money survey; Dunn, Son and Stone.

Cheesbrough, M. 2000. District laboratory practice in tropical countries, Part 2. Cambridge University Press, Cambridge, UK.

Cooper, E. 1991. Intestinal parasitoses and the modern description of diseases of poverty. Transactions of the Royal Society of Tropical Medicine and Hygiene 85(2): 168-170.

El-Dars, F.M. and W.M. Hassan. 2005. A preliminary bacterial study of Egyptian paper money. International Journal of Environmental Health Research 15(3): 235-239.

Emori, T.G. and R.P. Gaynes. 1993. An overview of nosocomial infections, including the role of the microbiology laboratory. Clinical Microbiology Review 6(4): 428-442. 
Food Science Australia (FSA). 2000. Money handling in food service operations. Food Safety and Hygiene. A bulletin for the Australian Food Industry.

Gadsby, P. 1998. Filthy lucre-Money contaminated with bacteria. Discover 19: 76.

Gilchrist, M.J.R. 1993. Microbiological culturing of environmental and medical device surfaces. Washington, DC, American Society for Microbiology.

Goktas, P. and G. Oktay. 1992. Bacteriological examination of paper money. Microbiological Bulletin 26(4):344-8.

Gwatkin, D.G., M 2000. The burden of disease among the global poor. The World Bank, Washington, D.C.

Jiang, X. and M.P. Doyle. 1999. Fate of Escherichia coli $\mathrm{O} 157: \mathrm{H} 7$ and Salmonella enteritidis on currency. Journal of Food Protection 62(7): 805-807.

Khin Nwe, O., W. Phyu Phyu et al. 1989. Contamination of currency notes with enteric bacterial pathogens. Journal of Diarrhoeal Diseases Research 7(3-4): 92-94.

Michaels, B. 2002. Money and serving ready-to-eat food. Food Service Technology 2(1): 1-3.

News, D. J. 1998. Add to the evils of money the fact it carries many germs.

Pinner, R.W., S.M. Teutsch, L. Simonsen, L.A. Klug, J.M. Graber, M.J. Clarke, R.L. Berkelman. 1996.
Trends in infectious diseases mortality in the United States. The Journal of the American Medical Association 275(3): 189-193.

Podhajny, M.R. 2004. How dirty is your money? Paper, Film \& Foil Converter (PFFC). Penton Media, Inc. 330 N. Wabash, Suite 2300, Chicago, IL 60611-3698

Pope, T.M., P.T. Ender, W. K. Woelk, M.A. Koroscil and T.M. Koroscil. 2002. Bacterial contamination of paper currency. Southern Medical Journal 95: 1408-1410.

Prasai, T., K.D. Yami and D.R. Joshi 2008. Microbial Load on Paper/Polymer Currency and Coins. Nepal Journal of Science and Technology 9:105-109.

Siddique, S. 2003. Dirty money. You're carrying more than cash in your wallet. Philippine Headline News online

Singh, D.V., K. Thakur, A. Goel. 2002. Microbiological Surveillance of Currency. Indian Journal of Medical Microbiology 20(1): 53.

Spivack, N. 2005. The threat of contaminated money: Proposed solutions. Minding the Planet. Retrieved from http:/novaspivack.typepad.com/ nova_spivacks_weblog/2005/02/

Struthers, J.K. and R.P. Westran. 2003. Clinical bacteriology. ASM Press, Washington, DC.

WHO. 2000. Overcoming antimicrobial resistance. Report on infectious diseases. World Health Organisation

$\mathrm{Xu}$, J., J. E. Moore et al. 2005. Ribosomal DNA (rDNA) identification of the culturable bacterial flora on monetary coinage from $17^{\text {th }}$ currencies. Journal of Environmental Health 67(7): 51-55. 